\title{
Palatalisation of /s/ in Afrikaans ${ }^{1}$
}

\author{
Daan Wissing and Wikus Pienaar \\ Centre for Text Technology (CTexT®), North-West University, Potchefstroom, South Africa \\ E-mail: daan.wissing@nwu.ac.za; wikus.pienaar@nwu.ac.za \\ Daniel van Niekerk \\ Multilingual Speech Technologies (MuST), North-West University, Vanderbijlpark, South Africa \\ E-mail: daniel.vanniekerk@nwu.ac.za
}

\begin{abstract}
This article reports on the investigation of the acoustic characteristics of the Afrikaans voiceless alveolar fricative $/ \mathrm{s} /{ }^{2}$. As yet, a palatal $[S]$ for $/ \mathrm{s} /$ has been reported only in a limited case, namely where /s/ is followed by palatal / $\mathrm{j} /$, for example in the phrase $i$ s jy ("are you"),

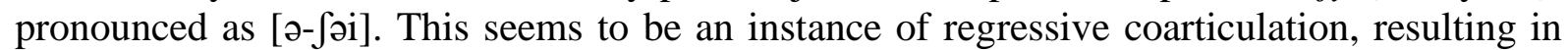
coalescence of basic /s/ and /j/. The present study revealed that, especially in the pronunciation of young, white Afrikaans-speakers, /s/ is also palatalised progressively when preceded by $/ \mathrm{r} /$ in the coda cluster $/ \mathrm{rs} /$, and, to a lesser extent, also in other contexts where $/ \mathrm{r} /$ is involved, for example across syllable and word boundaries. Only a slight presence of palatalisation was detected in the production of $/ \mathrm{s} /$ in the speech of the white, older speakers of the present study. This finding might be indicative of a definite change in the Afrikaans consonant system. A post hoc reflection is offered here on the possible presence of $/ \mathrm{s} /-$ fronting, especially in the speech of the younger females. Such pronunciation could very well be a prestige marker for affluent speakers of Afrikaans.
\end{abstract}

Keywords: Afrikaans, Acoustic features, Centre of Gravity, Palatalisation, /s/-fronting, Voiceless sibilant fricatives

\section{Introduction}

The Afrikaans /s/ is generally accepted to be a voiceless alveolar fricative. A coarticulatory process may result in a palatal allophone [J], similar to the palatal English phoneme in words

\footnotetext{
${ }^{1}$ This research was financially supported by the National Research Foundation (NRF) of South Africa. Opinions expressed, and conclusions arrived at are those of the authors and are not necessarily to be attributed to the NRF. ${ }^{2}$ Given that this is a study of the phonetic characteristics of the voiceless alveolar and palatal sibilant fricatives of Afrikaans, these two consonants, and the combinations thereof are presented with the phonetic symbols in square brackets [ ], except when they are specifically being dealt with in a phonemic sense, in which case the conventional slash symbols / / will be used. This is applicable to other characters too, such as the palatal fricative [j] in the next sentence.
} 
like ship or bush. This happens in cases where /s/ is followed by the palatal consonant /j/, for

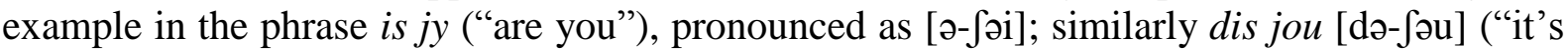
your") and was julle [va-fœlə] ("were you"). It might be described as a form of regressive assimilation, more specifically palatalisation. Remarkably, this specific type of palatalisation has gone unattended in the Afrikaans literature. Authors, including the following, do not mention such a process at all: Le Roux and Pienaar (1927); Wissing (1971); De Bruto and Wissing (1972); Coetzee (1981); Wissing (1984); Combrink and De Stadler (1987); De Villiers and Ponelis (1987).

Recently, a very similar allophonic realisation was observed ${ }^{3}$ for the Afrikaans phoneme /s/, this time surfacing in close proximity to the trill consonant $/ \mathrm{r} /$. Dissimilar to the

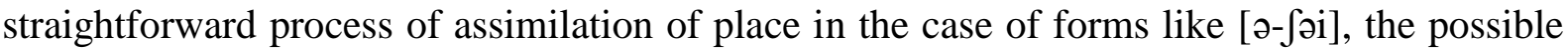
assimilatory influence of $/ \mathrm{r} /$ is all but straightforward.

This article firstly reports on a number of studies in which a possible occurrence of such a process was investigated. A variety of research methods, both formal and informal was used. Firstly, the presence of the hitherto unnoticed [S] in Afrikaans in the vicinity of $/ \mathrm{r} / \mathrm{is}$ documented. As a matter of convenience, reference is made to this realisation with the cover label of palatalisation. At the same time, in all appropriate situations, the product of such a process was denoted, in the case of the phoneme /s/, as [J], even though in some cases the alleged status of this allophone of /s/ is as yet uncertain.

Secondly, the role of syllable structure and vowel quality in the manifestation of such palatalisation is looked into briefly. And, lastly, the methodological issue of experimentally collected data and spontaneous speech data is considered.

In order to understand the specific phonetic characteristics of [ $]$ ] better in comparison with that of [s], a brief exposition of the articulatory and acoustic features of these fricatives is presented in the following section.

\section{2. $\quad$ Features of $[s]$ and $[f]$}

\subsection{Articulatory features of [s] and [J]}

The voiceless alveolar sibilant fricative /s/ is pronounced with the tip or blade of the tongue almost against the alveolar ridge just behind the teeth, e.g. in the onset consonant of the English word sip. In English, unlike Dutch, [s] has a strong hissing sound.

Cross-linguistically, $\left[\int\right]$ is a less common consonant, generally described in articulatory terms as a voiceless palato-alveolar fricative, also named postalveolar, articulated with the blade of the tongue slightly posterior to the alveolar ridge. The front of the tongue is domed at the palate. In some instances, lip-rounding is also present. Figure 1 shows the place of articulation and the cavities.

\footnotetext{
3 This observation was pointed out by Prof. Andries Coetzee of the Linguistics Department, University of Michigan, USA during a recording session of an extensive wordlist in which the words bas, bars, pas, pars were recorded. Note that there we were interested in the acoustic features of the initial consonants, /b, p/, and the following vowel, in this case /a/. Thus, we did not focus on the fricatives mentioned. We also would like to express our sincere gratitude for his valuable comments and recommendations on the prefinal draft of this article.
} 


\section{Lip rounding and sublingual cavity give [J] a much longer front cavity.}
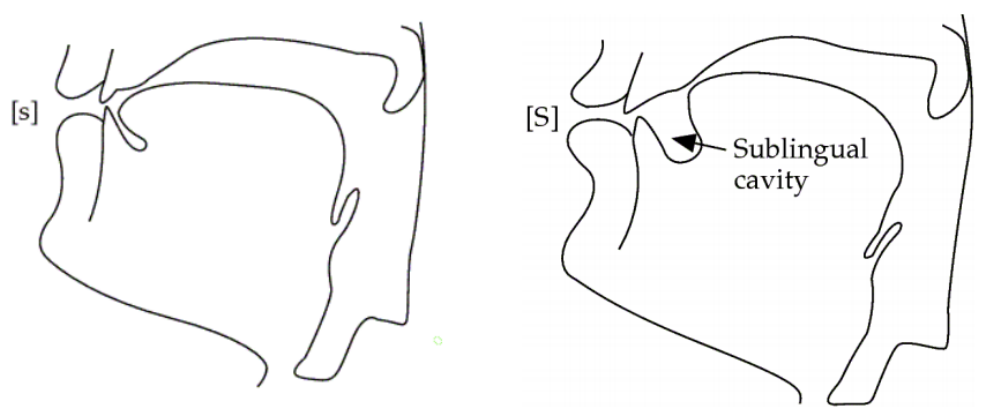

Figure 1. Articulation of [s] and [S] (sketch courtesy Johnson: http://linguistics.berkeley.edu/ 〜kjohnson/ling110/Lecture_Slides/8_Acoustics/fricative_acoustics.pdf).

The overall spectral features of fricatives are determined by the size and shape of the oral cavity in front of the constriction and therefore [s] and [S] are distinctly different acousticly. The precise meaning of this will be explicated in the next section.

\subsection{Acoustic features of $[s]$ and $\left[\int\right]$}

The longer front cavity of $\left[\int\right]$ compared to that of [s] translates into a fricative of distinctly different acoustic characteristics. While both [s] and [ $]$ ] are produced with high-intensity and spectrally distinct aperiodic energy, spectral analyses invariably show a relatively higher prominence for [s] in the higher frequency regions compared to [ $]$ ]. This is due to the smaller resonating cavity in front of the constriction in the case of [s] (Stevens 1988) - see Figure 1.

It is normal practice to analyse and express the acoustic characteristics of fricatives in terms of the spectral moments thereof. In the present study the algorithms of Praat (Boersma and Weenink 2014) were used as plug-in software for the calculation of the following four spectral moments. The authors interpret them as follows (see Praat's Help ${ }^{4}$ for more information):

Moment 1: The spectral centre of gravity $(\mathrm{CoG})$ is a measure for how high the frequencies in a spectrum are on average.

Moment 2: The standard deviation is a measure for how much the frequencies in a spectrum can deviate from the $C o G$.

Moment 3: The skewness is a measure for how much the shape of the spectrum below the $C o G$ is different from the shape above the mean frequency.

Moment 4: The kurtosis (referring to the 'sharpness' of the CoG-peak) is a measure for how much the shape of the spectrum around the $C o G$ is different from a Gaussian shape.

Note that, in all cases, the CoG is a basic concept in each of the four moments. Therefore, it is quite understandable why in the majority of investigations into the spectral features of

\footnotetext{
${ }^{4}$ See http://www.fon.hum.uva.nl/praat/manual/Spectrum.html.
} 
fricatives in general, and the sibilants in particular, Moment 1 is the most important and sometimes the sole acoustic parameter to be used. Strictly speaking, the size of the speaker's vocal tract should be taken into account here.

Jongman, Wayland and Wong (2000: 1253) give a comprehensive overview and description of the four moments. Moment 1 reflects the average energy concentration in the spectrum; Moment 2 encapsulates the range thereof. Moment 3 is an indicator of a distribution's asymmetry: a skewness of zero indicates a symmetrical distribution around the mean while in the case of a positive value the right tail of the spectrum extends further than the left. Alternatively, skewness is negative when the left tail of the distribution extends further than the right tail. Positive skewness suggests a negative tilt with a concentration of energy in the lower frequencies, whereas a negative skewness is associated with a positive tilt and a predominance of energy in the higher frequencies. Kurtosis is an indicator of the peakedness of the distribution. Positive values indicate a relatively high peakedness. The higher the value, the more peaked the distribution. Negative values indicate a relatively flat distribution. Positive kurtosis thus suggests a clearly defined spectrum with well-resolved peaks, while negative kurtosis indicates a flat spectrum without clearly defined peaks.

Numerous studies have examined the English fricatives - most including [s] and [S] - for example Daniloff, Wilcox and Stephens (1980); McGowan and Nittrouer (1988); Whalen (1991); Boothroyd and Medwetsky (1992); Shapiro (1995); Flipsen Shriberg, Weismer, Karlsson and McSweeny (1999); Jongman et al. (2000); Gordon, Barthmaier and Sands (2002); Munson (2004); Haley, Seelinger, Mandulak and Zajac (2010); Iskarous, Shadle and Proctor (2011); Koenig, Shadle, Preston and Mooshammer (2013). Mielke, Baker and Archangeli (2010) is a rare exception in dealing with allophony. Perkell, Matthies, Tiede, Lane, Zandipour, Marrone and Guenther (2004) investigate a possible positive correlation between the production and perception of these fricative consonants.

In most of the studies on English fricatives, Moment 1, that is the CoG, turned out to be a robust discriminator between the two sibilant fricatives /s/ and / $/$. Jongman et al. (2000: 1254) report typical averages for American English (10 male, 10 female speakers) of $6133 \mathrm{~Hz}$ for $/ \mathrm{s} /$, and $4229 \mathrm{~Hz}$ for $/ \mathrm{g} /$.

Little is known about the acoustic features of fricatives in languages other than English. Gordon et al. (2002) is an exception: they mention studies on Russian, French, Swedish, Polish, Portuguese, Arabic, Mandarin Chinese, Japanese and German, though without giving details concerning the $\mathrm{CoG}$ of the relevant fricatives. In addition, they studied the acoustic features of the fricatives of seven endangered American-Indian languages, viz. Aleut, Apache, Chickasaw, Hupa, Montana Salish, and Toda, as well as Scottish Gaelic. However, they only report on the first moment of spectral energy distribution, CoG. The average CoG of these languages' /s/ is $4906 \mathrm{~Hz}$, compared to $4535 \mathrm{~Hz}$ for $/ \mathrm{s} /$; the former notably lower than the American English $(6133 \mathrm{~Hz})$ reported by Jongman et al. (2000), and more in line with that of Dutch. For Dutch, Kwakkel (2008) gives the CoG of /s/ and $/ \mathrm{J} /$, for female speakers, produced in coda position, as $5410 \mathrm{~Hz}$ for /s/ and $3425 \mathrm{~Hz}$ for $/ \mathrm{g} /$. This is notably higher that the CoGs for male speakers, viz. $3849 \mathrm{~Hz}$ in the case of /s/, and $2804 \mathrm{~Hz}$ for $/ \mathrm{J} /$.

The general trend to be noted from these studies is, firstly, that the CoG values of the alveolar fricative [s] are distinctly higher than that of [J]. Secondly, a wide range of CoG values is 
evident, from a rather low $2 \mathrm{kHz}$, up to $6 \mathrm{kHz}$. The gender of speakers should also be taken into consideration. Interspeaker differences are evident too, as is seen in all of the studies that provide the individual CoG measurements.

Finally, CoG is by far the most important measurement in the investigations mentioned above. In contrast, the other three moments are seldom inspected. Consequently, in view of the exploratory nature of the current contribution, CoG seems to be the most appropriate parameter for this purpose.

\subsection{Empirical studies}

In the following few sections, a series of studies relating to the realisation of $/ \mathrm{s} /$ when preceded by $/ \mathrm{r} /$ is provided. A general working hypothesis might be the following:

H1:

The voiceless alveolar fricative /s/, when preceded by $/ \mathrm{r} /$, is pronounced as $\left[\int\right]$ in Afrikaans.

This hypothesis was tested in Study 1. This study is exploratory in nature, and therefore confined to the realisation of /s/ in word-final coda positions in structures like Xas and Xars. In subsequent studies /s/ was investigated among other speakers and in various different types of structures, in particular across different types of boundary, namely syllable boundaries ('\$'), morpheme boundaries ('+') and word boundaries within phrases ('\#\#’).

\section{Data collection}

\subsection{Method}

In this section, details are presented concerning the recording of speech data and procedures followed in the analysis of the data.

\subsection{Recordings}

In all cases reported here, suitable recording equipment was used. Except for the recordings for Study 3, where a handheld recorder was used ${ }^{5}$, professional equipment was used in soundtreated studios. For Study 1 and 2 an AKG C1000S cardioid/hypercardioid condenser type microphone was used. The recordings for Study 4 took place in a recording studio of Radio sonder Grense (RSG). Here the microphone was a Shure /SM7B, cardioid dynamic voiceover-microphone. In all these cases the recordings were made at a sampling rate of $44.1 \mathrm{kHz}$, 32 bit sample size. Crowd-sourcing on campus, mentioned in the last section, was performed with a hand-held Philips DVT3500 recorder, also at a sampling rate of $44.1 \mathrm{kHz}$.

\subsection{Analytic procedures}

All recordings were first orthographically transcribed, whereafter the recordings together with their associated transcriptions were processed as follows by automatic phonetic alignment:

\footnotetext{
${ }^{5}$ Specifications are not known.
} 
The orthographic transcriptions (sentences) were converted into their expected phonetic forms using letter-to-sound (grapheme-to-phoneme) rules extracted from an existing Afrikaans pronunciation dictionary (Davel and De Wet 2010) using the Default \& Refine algorithm (Davel and Barnard 2008). Statistical models (Hidden Markov Models - HMMs) were estimated, given the expected phonetic sequences and recordings as described in Van Niekerk and Barnard (2009). These models were used to find an alignment between the phone sequence and the audio sequence (using forced-alignment: a constrained form of speech recognition).

The final results of this process are exact time instants (to the nearest audio frame, i.e. 5 milliseconds) for where the expected phones start and end. This information can then be viewed in Praat as a TextGrid and used to inspect the obtained alignments for correctness in the contexts of interest. During this process, two systematic deviations from the predicted phonetic sequences were detected and manually corrected (omitted from our subsequent analyses): (i) some cases where the /r/ preceding an /s/ was almost completely absent, and (ii) cases where due to the known process of regressive assimilation of voicing the $/ \mathrm{s} /$ following an $/ \mathrm{r} /$ was pronounced as [z]. After updating the alignments in this way, the relevant data was subject to the following step of calculating the spectral CoG (automated as a Praat script): On the basis of the alignment information, all sound samples of interest were excised, i.e. all cases of /s/ occurring in the audio. For each of these samples, Praat was used to firstly determine the spectrum (using the Fast Fourier Transform) and secondly to calculate the $\mathrm{CoG}$, which represents the average frequency in the relevant spectral slice. The result for each sample was a single CoG value.

The CoG is calculated by taking a weighted average of the frequencies occurring in the spectral slice, so that frequencies with a higher intensity contribute more towards determining the average frequency (Boersma 2001). This reduces the series of numbers representing the spectrum to a single frequency value, which correlates well with perception of the sound, thereby allowing efficient analysis using standard statistical methods.

\section{The experiments}

In the next section, the results of a series of investigations of alleged palatalisation of $/ \mathrm{s} /$ to $\left[\int\right]$ are presented. On the basis of what has been said before about the possibility of the occurrence of this process in Afrikaans, Hypothesis 1 was firstly tested in Study 1. As noted previously, the study was exploratory in nature, i.e. confined to /s/ in word-final coda position, namely in Afrikaans words with the structures Xas (bas and pas) and Xars (bars and pars). In subsequent studies, other types of boundary were taken into account, i.e. syllable ('\$'), morpheme ('+'), lexical boundaries within compound words ('\#'), and in a few cases word boundaries within phrases ('\#\#').

\subsection{Study 1: productions of /s/ by two groups}

Here the basic findings are presented of the inspection of the readings of the four words bas, bars, pas and pars by 20 female speakers, 10 of them elderly (50 - 67 years) and 10 young (18 - 23 years). The recordings were used in a separate study on the acoustic features of Afrikaans voiceless and voiced plosives $(/ \mathrm{p}, \mathrm{b}, \mathrm{t}, \mathrm{d}, \mathrm{k} /)$ in onset position, as well as that of the vowels following them (Coetzee, Beddor and Wissing 2014). For our purposes the quality of recordings was sufficient. These words formed part of a list of 110 words. Each word was 
read eight times by the 20 participants, rendering 17600 cases $(20 \times 8 \times 110)$. For current purposes, four useable cases were selected of each word ending on -as and-ars, providing 160 useable tokens.

\subsubsection{Results of Study 1}

Table 1 contains the results of the measurement of the CoG of /s/ directly after a vowel (CVs: bas/pas) and after a vowel plus /r/ (CVrs: bars/pars), both in pre-pausal position. As a matter of convenience, $\mathrm{CV} \_$s referred to as a non-palatalised context, while $\mathrm{CVr}_{-}$is referred to as a palatalising context.

A distinct difference between these two contexts is obvious; in terms of Cohen's effect size inde ${ }^{6}$ (Cohen 1988). The value of $d=1.84$ indicates a highly practically significant difference $^{7}$. In most cases palatalised [ $\left.\int\right]$ was distinctly audible as such in the recordings. This is in keeping with the finding of, inter alia, Forrest, Weismer, Milenkovic and Dougall (1988).

Table 1: CoG of the realisation of /s/ in the four words bas, bars, pas, and pars, as produced by 20 speakers of Afrikaans.

\begin{tabular}{|l|r|r|r|}
\hline & Mean & $\mathrm{N}$ & s.d. \\
\hline Non-palatalising context (CVs) & 6829 & 160 & 1165 \\
\hline Palatalising context ( CVrs ) & 4684 & 160 & 536 \\
\hline
\end{tabular}

In addition, the results shown in this table are in line with those reported by Jongman et al. (2000) for American English, in their case $6133 \mathrm{~Hz}$ for /s/, and $4229 \mathrm{~Hz}$ for / $/$. Equally importantly, an overall difference was found between the productions of the two age groups as shown in Figure 2.

\footnotetext{
${ }^{6}$ Effect size indexes in terms of d-values are calculated by the following formula (cf. Cohen, 1988): $\frac{\text { Mean A-Mean } 2}{\text { largest standard deviation }}$. This index is used for determining the significance of the difference. $d>0.20$ denote no significant difference; $0.20<\mathrm{d}>0.50$ (equals a small effect); $0.50<\mathrm{d}>0.80$ (a moderate effect) and $\mathrm{d}>0.80$ (a large effect). Basic and Applied Social Psychology, in an editorial, emphasised that the null hypothesis significance testing procedure (NHSTP) is invalid, and thus authors were discouraged from using it (Trafimow 2014). The same word of caution goes for the use of confidence intervals. This journal requires "strong descriptive statistics, including effect sizes", what we strive to do as far as possible in the present article.

${ }^{7}$ Henceforth, we only specify effect sizes as significantly different or not. Thus the specification of "practical" is always implied.
} 


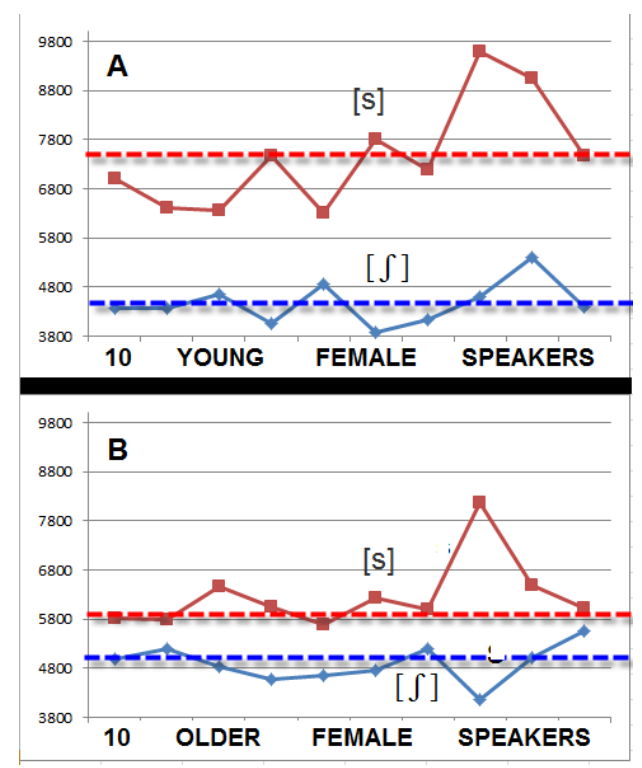

Figure 2. CoG of the realisation of /s/ in the two contexts CVs and CVrs by two groups of female speakers (10 young (Window A) and 10 older (Window B)). Speaker's numbers (\#1 \#10) refer to the 10 squares from left to right.

The top panel in this figure shows the CoG for each of the 10 younger speakers in our study, and the bottom panel for the older speakers. In each panel, the bottom broken lines mark the average CoG for / $/ \mathrm{f}$ in CVrs context (i.e. in pars and bars) while the top ones mark the average $\mathrm{CoG}$ for /s/ as produced in the CVs context (i.e. in pas and bas). From this figure it is clear that the $\mathrm{CoG}$ difference between the two contexts is much larger for younger than older speakers, indicative of younger speakers having more distinct allophonic realisations for $/ \mathrm{s} /$. Note that there is variation within each group with at least one older speaker showing a pattern very similar to that of the younger speakers. For the rest of the young speakers' CoGs, it might be stated that there is a strong tendency towards palatalisation in the CVrs context. Such a conclusion is supported by listening to the pronunciations of these speakers, as well as by visual inspection of these speakers when they pronounced the relevant words. Table 2 shows the details for the older group of speakers separately, as does Table 3 for the younger group.

Table 2. CoG of the realisation of /s/ in the four words bas, bars, pas and pars, as produced by 10 older speakers of Afrikaans.

\begin{tabular}{|l|r|r|r|}
\hline & Mean & $\mathrm{N}$ & s.d. \\
\hline Non-palatalising context (CVs) & 6309 & 80 & 839 \\
\hline Palatalising context (CVrs ) & 4888 & 80 & 497 \\
\hline
\end{tabular}

Table 3. CoG of the realisation of /s/ in the four bas, bars, pas, and pars, as produced by 10 young speakers of Afrikaans.

\begin{tabular}{|l|r|r|r|}
\hline & Mean & $\mathrm{N}$ & s.d. \\
\hline Non-palatalising context (CVs) & 7352 & 80 & 1215 \\
\hline Palatalising context (CVrs ) & 4479 & 80 & 496 \\
\hline
\end{tabular}


Both groups display a significant difference between /s/ in the two contexts, with the young group's $d=2.36$ markedly higher than that of the older group $(d=1.69)$. This difference is clearly visible in Figure 2. The difference between the [s] of the two groups $(7352 \mathrm{~Hz} \mathrm{vs}$. $6309 \mathrm{~Hz})$ is also significant $(\mathrm{d}=0.86)$, though not as distinct as the other two d-values.

\subsection{Study 2: production of /s/ by two individuals}

The results of Study 1 prompted a follow-up study in which the production of the two fricatives by two speakers of that study was more closely inspected, one the clear palataliser (\#8 in Figure 2, B), the other one evidently not (\#2). The present study focuses on the CoGs of $[\mathrm{s}]$ and $\left[\int\right]$ in contexts broader than coda position. A similar result was expected on the basis of extensive preliminary informal observations. The reading material, read three times by each participant, comprised a list of words and phrases, in which /s/ occurred in $\mathrm{CVr}_{-}$as well as $\mathrm{CV}_{-}$context.

\subsubsection{Results of Study 2}

In Table 4 the results of two speakers are presented and compared. These speakers were selected from the list of older speakers in Study 1 as a clear palataliser, and the other as a clear non-palataliser.

Table 4. CoG of /s/ in two contexts, as produced by two older speakers of Afrikaans, one a palataliser, one non-palataliser.

\begin{tabular}{|l|r|r|r|}
\hline PALATALISER & Mean & $\mathrm{N}$ & s.d. \\
\hline Non-palatalising context $(\mathrm{CV} \underline{\mathrm{s}})$ & 6209 & 34 & 632 \\
\hline Palatalising context CVrs & 2932 & 75 & 512 \\
\hline \multicolumn{3}{|l|}{} \\
\hline NON-PALATALISER & Mean & $\mathrm{N}$ & s.d. \\
\hline Non-palatalising context & 4971 & 33 & 380 \\
\hline Palatalising context (post /r/) & 4308 & 74 & 411 \\
\hline
\end{tabular}

Both readers have distinct pronunciations for the two fricatives, although the very low $2932 \mathrm{~Hz}$ in $\mathrm{CVr}_{-}$context unmistakably indicates a more profuse palatalisation by the Palataliser $(\mathrm{d}=5.2)$, than the Non-palataliser $(\mathrm{d}=1.7)$; the Palataliser's much larger effect size indicates that the Palataliser indeed palatalises to a greater extent than the Nonpalataliser. Important too, however, is the distinct difference between the two speakers when it comes to /s/ in the $\mathrm{CV}_{-}$context.

Visual inspection of the productions by the two speakers clearly showed different lip positions when producing /s/ in the two contexts. Figure 3 is a photograph of Palataliser's lip positions at the peak moment of producing /s/ in bas and bars. Note the greater openness of the lips in the right panel, as well as the clear visibility of all the underteeth. Lip rounding thus seems to be a characteristic of excessive palatalisation, perhaps to be labelled labialisation. This matter is a topic worth future investigation. 


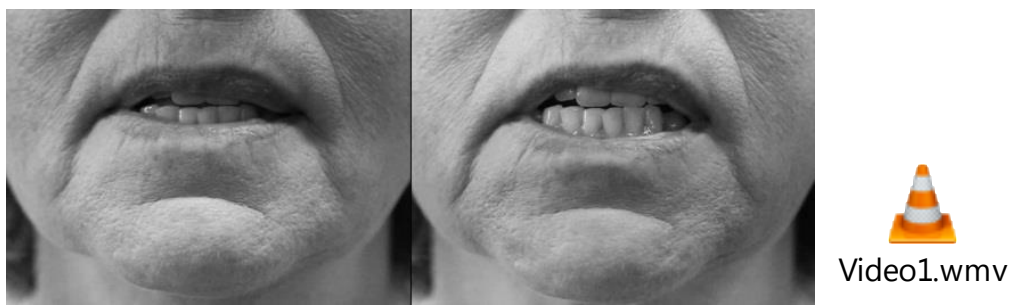

Figure 3. Photograph of lip position of the Palataliser at the peak moment of production of [s] in bas (left picture) and [J] in bars (right picture). Click on Video1.wmv to see and listen to the complete recording.

The results of Study 2 support H1 in the case of both speakers, but significantly more in the case of the palatalising subject.

\subsection{Study 3: production of /s/ by Prototypical Speaker 1}

In this study a somewhat larger and more precisely constructed speech data set was collected, still mainly for exploratory reasons. Christelle Webb-Joubert (henceforth CWJ), a well-known radio presenter on the Afrikaans station Radio Sonder Grense (RSG), gave her consent for not only recording her, and analysing the recordings for the purpose of this study, but also gave us permission to disclose her name. By merely listening to CWJ's radio presentations a profuse palatalising of $/ \mathrm{s} /$ when preceded by $/ \mathrm{r} /$ is striking.

The somewhat more elaborate character of the present investigation necessitates a careful presentation of details concerning the reading tasks as well as the procedures used.

\subsubsection{Reading materials}

The CoG of the realisation of 224 cases of /s/ in a number of contexts (see also Table 3) was the focus of this study, which involved the reading of a word list (Task 1) and some relevant sentences (Task 2). For the purposes of this study ' + ' and ' $\$$ ' (being labelled multisyllabic words, indicated by ' $\$ /+$ ') were pooled together as consituting one context.

In total, 32 syllable-internal CVrs structures (as in broe $\underline{\text { s }}$ ) occurred in Task 1, and 24 in Task 2. In 40 cases of Task $2 / \mathrm{r} /$ and /s/ were on either side of syllable boundaries (as in ver $\$ \underline{\text { staan). }}$ ). Furthermore, in Task 2, 20 instances occurred across a word-boundary, for example maar \#\# seker. Only eight compounds, all of them in Task 1, were present (e.g. voor $\underline{\text { t }}$ skote).

\subsubsection{Results of Study 3}

The focus of this study is on the different ways in which /s/ in $\mathrm{CVr}_{\text {_ }}$ context realises phonetically in the different contexts as described in the previous section, as well as /s/ in non-palatalising $\mathrm{CV}_{-}$context. Table 5 shows the respective measurements. 
Table 5. CCoG of $/ \mathrm{s} /$ in palatalising (post $/ \mathrm{r} /$ ) and non-palatalising contexts. (Contexts are numbered from 1 to 5 .)

\begin{tabular}{|l|r|r|r|}
\hline & Mean & $\mathrm{N}$ & s.d. \\
\hline $1 . / \mathrm{s} /$ after $/ \mathrm{r} /$ in coda cluster (rs\#\#) & 3646 & 59 & 1189 \\
\hline $2 . / \mathrm{s} /$ after /r/ in bimorphemic context $(\mathrm{r}+\mathrm{s})$ & 3748 & 16 & 773 \\
\hline $3 . / \mathrm{s} /$ after /r/ in bisyllabic context $(\mathrm{r} \$ \mathrm{~s})$ & 4658 & 32 & 713 \\
\hline $4 . / \mathrm{s} /$ after $/ \mathrm{r} /$ in phrase context $(\mathrm{r} \# \# \mathrm{~s})$ & 5008 & 31 & 1268 \\
\hline $5 . / \mathrm{s} /$ in contexts other than next to /r/ & 5765 & 86 & 952 \\
\hline
\end{tabular}

Note that in principle $\mathrm{r} \$ \mathrm{~s}$ can overlap with both $\mathrm{r}+\mathrm{s}$ and $\mathrm{r \# s}$, while the latter two boundary types, + and \#, always imply a syllable boundary, $\$$.

There are significant differences between unmarked /s/ in Context 5 on the one hand, and each of the other four contexts on the other hand $(\mathrm{d}>1.16)$. In general, the raw CoG numbers indicate a diverse situation, from very small differences, notably between Context 1 , that is in the same coda, and Context $3(\mathrm{~d}=0.08)$. A significant difference is present between Context 1 and Context $4(\mathrm{~d}=1.07)$. Of interest is the clear difference between the contexts where syllable and morpheme boundaries are involved, viz. Context 2 and Context $3(\mathrm{~d}=1.17)$. Such differences are also supportive of the psychological reality of boundaries, notably in this case syllable and morpheme boundaries.

The following strength hierarchy (SH1) of palatalisation may be postulated ${ }^{8}$ on the basis of the current results of CWJ (from most to least degree of palatalisation):

SH1:

Context $1>$ Context $3>$ Context $2>$ Context $4>$ Context 5

where:

Context 1 = syllable internal; in word and syllable final coda cluster -rs

Context 2 = bimorphemic structure, with $/ \mathrm{r} /$ to the left of a syllable boundary $(\$)$, and /s/ to its right

Context 3 = bimorphemic structure, with $/ \mathrm{r} /$ to the left of a morpheme boundary $(+)$, and /s/ to its right

Context $4=$ a phrase structure, with /r/ to the left of a phrase boundary (+), and /s/ to its right

Context $5=$ structures where $/ \mathrm{s} /$ is not preceeded by an $/ \mathrm{r} /$

On the basis of this hierarchy, one could propose the following hypotheses $\mathbf{H 2}$ :

\footnotetext{
${ }^{8}$ Of course this is a very tentative one; the current numbers of measurements are indeed very low. But at the same time it could serve as a starting point for further analyses.
} 
(i) Syllable structure matters: there is greater palatalisation when $/ \mathrm{r} /$ and $/ \mathrm{s} /$ are in the same syllable than when they are in different syllables (more in broers than in ver\$staan) [rs\#\# > r\$s].

(ii) Morphology matters: there is greater palatalisation across a morpheme boundary than across a syllable boundary (more in ver $\$$ staan than in in ver+skrik). [r\$s $>\mathrm{r}+\mathrm{s}]$.

(iii) Syntax matters: there is greater palatalisation across a morpheme boundary than a phrase boundary (more in ver+skrik than in voor \# $\underline{s} e s$ ). [ $\mathrm{r}+\mathrm{s}>\mathrm{r} \# \mathrm{~s}]$.

(iv) Hypothesis (iii) may be extended to:

There is more palatalisation across syllable boundaries than across phrase boundaries (more in ver\$staan than in voor\#ses). [r\$s > r\#s].

\subsection{Study 4: production of /s/ by Prototypical Speaker 2}

In view of the results obtained thus far, the issue of palatalisation was subsequently investigated in a more elaborate and structured way. But at the same time other matters were looked into, notably the possible influences of vowel quality on (degree of) palatalisation.

The participation of another well-known RSG person, Mariëtta Kruger (henceforth MK), was obtained for this experiment. As a well-known radio broadcaster and TV presenter of Afrikaans programmes, her pronunciation in the present case could well serve as a prototypical example of modern Standard Afrikaans ${ }^{9}$.

\subsubsection{Speech materials}

An array of speech data sets was constructed, representative of the main types mentioned in previous sections. The speech materials were constructed with the testing of SH1 and $\mathrm{H} 2$ above in mind.

MK was recorded in the following ways, in RSG's professional studio, making use of professional recording equipment (see Section 3.2 above):

1. A spontaneous interview, comprising spontaneous speech about subjects such as her pets, her love for the radio as medium, and her experiences in Italy as prime tourism destination (nearly 15 minutes of speech; rendering 55 cases with /r/ plus /s/, and 574 with single /s/).

2. Two weeks later MK read 213 seconds of extractions from the orthographic transcription of the interview in 1 . These extractions were full sentences, comprising $39 / \mathrm{r} /+/ \mathrm{s} /$ structures, and 142 cases of pure /s/.

3. Separately from the interviews (1 and 2), MK also read the following speech materials. Each word was read three times:

a. Type rs\#\#

Single words with -rs as coda (e.g. broers, wors). In this case, all 12 of the vowels of Afrikaans were represented in rhyme position, that is, preceding

\footnotetext{
${ }^{9}$ In a recent listening experiment that was conducted online, using Google Forms, MK was placed first among some other radio presenters and lay speakers of Afrikaans with regard to acceptability to be a radio presenter, as well as the standardness of her Afrikaans pronunciation. For an inspection of this experiment, use the following link: http://goo.gl/forms/RhtFOfKS86.
} 
the -rs coda. This was to allow for the inspection of the role of vowel quality on possible palatalisation of $/ \mathrm{s} /$, more specifically though a process of progressive coarticulation. Secondly, two more sets of words (wors and dors; vers and kers) were added to carrier sentences (e.g. 'Wors rym met dors, maar nie met kers nie') ('Wors rhymes with dors, but not with kers'). This task was added to provide possible evidence for an influence of rounded vowels on /s/-palatalisation (in wors and dors), in contrast to unrounded vowels (in kers and vers).

b. Type $r \$ s$

Single multisyllabic words, with ver- as first syllable, (e.g. ver-sier), with /r/ as coda of the first syllable, and /s/ as onset of the following syllable (thus $r \$ s$ ). Here all the Afrikaans vowels (12 in total) were represented in the rhyme position of the final syllable.

c. Type $X r s Y$ - (i.e. $\mathrm{r}+\mathrm{s}$ and $\mathrm{r} \$ \mathrm{~s}$ )

Single multisyllabic words, with /r/ as coda of the first morpheme, and /s/ as onset of the following syllable (e.g. ver $+\underline{s} k r i k$, selfbeheer $\$ \underline{s i n g}$ ), or with $r s$ as coda, as in a. (e.g. luisteraars). This is thus a mixed list made up of different syllable structures.

In total 21 pure /s/ cases were present in these tasks, and 141 realisations of /s/ in the post-/r/ contexts, specifically, 60 instances of rs\#\#, 27 of $r \$ s$, and 51 of $r+s .{ }^{10}$

\subsubsection{Results of Study 4}

Here the productions of MK's fricatives in the tasks stated above are looked into, especially regarding the two contexts referred to in Study 3, viz. firstly CVrs, i.e. rs\#\# as word final coda cluster, and secondly with $/ \mathrm{r} / \mathrm{as}$ coda of the first syllable, and /s/ as onset of the following syllable (thus $r \$ s$ ).

\subsubsection{The interview types}

As to these types, that is Task 1 and Task 2, the presence or absence of an inclination towards palatalisation is firstly determined in the two tasks separately. A next step is to look for differences between the two tasks, and thus a comparison across the two tasks is offered of the productions of pure /s/, as well as for productions of $-r s^{11}$. In doing so, some light is cast on some methodological issues concerning the use of different types of speech materials in research similar to this.

\subsection{Task 1}

In the spontaneous interview, a moderate overall effect size difference $(\mathrm{d}=0.51)$ was found between the two types of fricatives (Table 6), which also means only a mild inclination towards palatalisation. With this result in mind, for reference in the following tasks, MK may provisionally be characterised as a moderate palataliser.

\footnotetext{
${ }^{10}$ Due to more examples of each of the contexts $r \$ s$ and $r+s$, we do not conflate them as before.

${ }^{11}$ From here on, -rs will serve as cover term for the different types of combinations of $/ \mathrm{r} /$ and $/ \mathrm{s} /$.
} 
Table 6. $\mathrm{CoG}$ of $/ \mathrm{s} /$ in the palatalising (post-/r/) and non-palatalising contexts in the spontaneous speech task.

\begin{tabular}{|l|r|r|r|}
\hline & Mean & $\mathrm{N}$ & s.d. \\
\hline Non-palatalising context & 5214 & 574 & 1224 \\
\hline Palatalising context (post /r/) & 4595 & 53 & 1202 \\
\hline
\end{tabular}

In Table 7 the different post /r/ contexts of MK's speech are specified.

Table 7. CoG of /s/ in four combinations with $/ \mathrm{r} /$ in the spontaneous speech task.

\begin{tabular}{|l|r|r|r|}
\hline & Mean & $\mathrm{N}$ & s.d. \\
\hline 1./s/ after/r/ in coda cluster (rs\#\#) & 4084 & 14 & 1100 \\
\hline 2./s/ after/r/ in bisyllabic context (r\$s) & 4459 & 12 & 1038 \\
\hline 3./s/ after/r/ in bimorphemic context (r+s) & 4474 & 11 & 1577 \\
\hline 4. /s/ after/r/ in phrase context (r\#s) & 5227 & 16 & 903 \\
\hline $5 . / \mathrm{s} /$ in contexts other than next to /r/ & 5214 & 574 & 1224 \\
\hline
\end{tabular}

Here too, as in Table 5, the presence of the boundaries + and \# imply \$. The interview context was, of course, not under experimental manipulation as in the case of the reading lists. Thus, despite about 15 minutes of speech during the interview, the number of cases of $/ \mathrm{s} /$ and $/ \mathrm{r} /$ in all contexts are low and therefore no strong conclusions can be advanced here.

There is a large difference $(\mathrm{d}=0.92)$ between Context $1(4084 \mathrm{~Hz})$ and Context $5(5214 \mathrm{~Hz})$. Context 1, with the lowest $\mathrm{CoG}$, is once again the strongest palatalising context, thus supporting SH1 as well as H2 (i), and, per implication, the other hypotheses. Note that r\#s (Context 4) is practically identical to pure /s/ (Context 5), which means that in fluent speech MK does not palatalise across words. In this respect, her spontaneous productions are not in support of $\mathrm{H} 1$. The similarity of $r+s$ and $r \$ s$ is obvious; thus also not in support of H2 (ii). On the other hand, H2 (iii)/(iv) is maintained to a moderate extent $(\mathrm{d}=0.62)$. Except for the similarity of Context 4 and 5, the strength hierarchy formulated on the basis of CWJ's productions (see Section 4.3) is the same for MK. Thus context matters not only here, but also to a high extent in the same manner.

\subsection{Task 2}

In this task, i.e. the reading of a portion of the spontaneous interview previously collected, an overall moderately significant difference between the two main contexts $(d=0.88)$ was found, as summarised in Table 8. 
Table 8. $\mathrm{CoG}$ of $/ \mathrm{s} /$ in the post-/r/ and other contexts in the reading of a portion of the spontaneous speech task.

\begin{tabular}{|l|r|r|r|}
\hline & Mean & $\mathrm{N}$ & s.d. \\
\hline Non-palatalising context & 6019 & 142 & 922 \\
\hline Palatalising context $($ post /r/) & 5201 & 38 & 804 \\
\hline
\end{tabular}

Table 9 is a more detailed presentation of the results of Table 8.

Table 9. CoG of $/ \mathrm{s} /$ in combinations with $/ \mathrm{r} /$ and in other contexts in the reading of a portion of the spontaneous speech task. Contexts are numbered in the first column.

\begin{tabular}{|c|c|c|c|}
\hline & Mean & $\mathrm{N}$ & s.d. \\
\hline 1. /s/ after /r/ in coda cluster (rs\#\#) & 4758 & 15 & 689 \\
\hline 2. $/ \mathrm{s} /$ after $/ \mathrm{r} /$ in bimorphemic context $(\mathrm{r}+\mathrm{s})$ & 5192 & 6 & 343 \\
\hline 3. /s/ after /r/ in bisyllabic context (r\$s) & 5755 & 8 & 1161 \\
\hline 4. /s/ after /r/ in phrase context (r\#s) & 5783 & 9 & 942 \\
\hline 5. /s/ in contexts other than next to $/ \mathrm{r} /$ & 6019 & 142 & 922 \\
\hline
\end{tabular}

According to Table 9 two classes of CoGs are evident, viz. Context 1 and 2 on the one hand, and the other three on the other. The large difference present in Table $8(\mathrm{~d}=0.88)$ is clearly observed by comparing these two classes. Furthermore, only small differences are present between the three classes, namely Context 2,3 and $4(\mathrm{~d}>0.25)$. This is a confirmation of the observation that MK does not palatalise in sentence contexts. /s/ CoGs in Context 3 and 4 are virtually identical. Note that, contrary to the situation in Task 1, here a moderate difference between Context 2 and 3 was obtained, with Context 2 the more likely of the two to induce palatalisation. This is in accordance with the strength hierarchy SH1, formulated earlier. However, one should be cautious not to take this result too seriously, due to the very low numbers of cases in the present task.

Of special interest for the focus of the present study is a direct comparison, across the two tasks, between the production of /s/ in Context 1 , namely the canonical palatalising post-/r/ context, in Table 7 and 9. On first sight, palatalisation is present to a larger degree in the spontaneous task $(4084 \mathrm{~Hz}$ vs. $4758 \mathrm{~Hz}$ ). However, note that the $\mathrm{CoG}$ of the pure /s/ of Context 5 is also relatively larger in the reading task $1(6019 \mathrm{~Hz})$ in comparison with the nonreading task $(5214 \mathrm{~Hz})$, indicative perhaps of a more careful pronunciation in the former.

A comparison was thus subsequently carried across the COGs of words and combination of words that appear in both tasks, namely the interview (Task 1) and the reading of the same material (Task 2). Seventeen identical pairs of $r s$ structures were found, for example eer $\underline{r}$, verslag and oor stories were present in both the spontaneous speech and the reading of a portion of that interview. This was meant to further investigate whether a possible higher tendency towards palatalisation may be present in one of the two modes of speaking. Table 10 presents the outcome of this analysis. 
Table 10. Comparison across the spontaneous interview and the reading of an identical portion with respect to the $\mathrm{CoG}$ of /s/ in the palatalising (post-/r/) context.

\begin{tabular}{|l|r|r|r|}
\hline & Mean & N & s.d. \\
\hline SPONTANEOUS & 4994 & 17 & 1015 \\
\hline READ & 5379 & 17 & 1365 \\
\hline
\end{tabular}

The raw Hertz measurements indicates a slightly higher tendency towards palatalisation of /s/ in the case of the spontaneous mode $(\mathrm{d}=0.28)$. Such inclination, albeit slight, is in line with what is to be expected in spontaneous versus read speech in general.

Due to the low numbers of available cases, no clear judgement could be made regarding the hierarchy strength of the position of /s/ in the three structures, viz. in coda position, with /s/ preceding morpheme/syllable boundary, or across words in phrases. What may be stated here, is that rs\#\# maintains its position as the strongest inducer of possible palatalisation.

The following two tasks provide somewhat larger sets of measurements of $\mathrm{CoG}$, so that the strength hierarchy can be assessed more confidently.

\subsection{Task 3}

Three subtasks were constructed to enable us to inspect the relative strength of three types of structures vis-a-vis palatalisation: Context 1 (rs\#\#), Context $2(\mathrm{r}+\mathrm{s})$ and Context 3 (r\$s). No instances of $\mathrm{r \# s}$ were present, due to the absence of phrases. Here the role of vowel-toconsonant coarticulation in the case of palatalisation was also possible to inspect.

\section{Vowel quality and palatalisation of $/ \mathrm{s} /$}

In Type 3a (see Speech materials) the words kers and vers were included, with unrounded vowels as nuclei, and also dors and wors, with rounded nuclei. This was to assess a possible special type of coarticulatory influence on the $\mathrm{CoG}$ of /s/. Figure 4 clearly depicts such influence. /s/ in coda clusters of words with rounded vowels (like wors) possesses a generally lower $\mathrm{CoG}$ than $/ \mathrm{s} /$ in words with unrounded vowels (e.g. kers). The same goes for $/ \mathrm{s} / \mathrm{in} \mathrm{r}+\mathrm{s}$ context s (versier vs. versuur). 


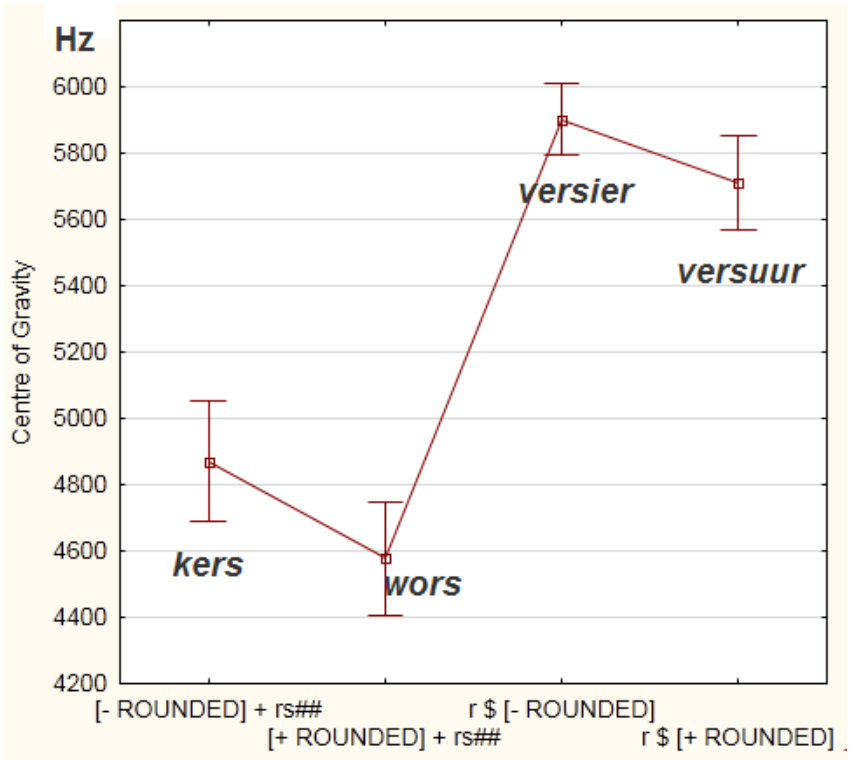

Figure 4. Influence of vowel quality (rounded or unrounded) on degree of palatalisation of /s/: means and \pm 0.95 confidence intervals. Examples of relevant cases are added.

\section{Production of /s/ by a group of Coloured Afrikaans-speakers}

Here a brief reflection is offered on the possibility of whether palatalisation is present in the speech of a group of Coloured ${ }^{12}$ individuals from the Western Cape, living in a homogeneous speech community in Genadendal since their birth. The speech data was obtained as produced by an equal number of elderly and young persons, male and female. A detailed analysis is not in place here and, therefore, only broad tendencies are provided, deduced from a fairly large data set $(n=2277)$.

In Table 11 the CoG of all the instances of /s/ when preceded by /r/, irrespective of broader context, are given, and likewise all instances of 'pure' /s/, that is in onset and in coda position.

Table 11. CoG of /s/ in two classes of context pooled, as produced by young and older participants.

\begin{tabular}{|l|r|r|r|r|r|r|r|}
\hline & \multicolumn{3}{|c|}{ YOUNG } & \multicolumn{3}{|c|}{ OLDER } \\
\hline & Mean & $\mathrm{N}$ & s.d. & & Mean & $\mathrm{N}$ & s.d. \\
\hline Palatalising post-/r/ contexts & 3934 & 169 & 893 & & 3612 & 149 & 876 \\
\hline Non-palatalising contexts & 4016 & 1087 & 937 & & 3829 & 872 & 983 \\
\hline
\end{tabular}

In both cases, that is, in the productions of both the young and the older participants, no significant differences were found (Young: $d=0.08$; Older: $d=0.22$ ). The conclusion here is then, that the Coloured speakers of Genadendal that were investigated as a whole do not palatalise /s/ when preceded by /r/. Interestingly however, the older speakers do not show a significant difference between the effect of the two different palatalising contexts, $r+s$ and rs\#\# $(\mathrm{d}=0.03)$, while these two contexts make a significant difference in terms of /s/-

\footnotetext{
${ }^{12} \mathrm{We}$ are aware of the debate concerning the term coloured in the South African context. Note that this group of people is referred to by this term in the census documents of Statistics South Africa.
} 
palatalisation in the young speakers' speech $(d=0.56)$; the greater extent of palatalisation is to be observed in the CoG of the rs\#\# context, viz. $3480 \mathrm{~Hz}$, compared to $3981 \mathrm{~Hz}$ for r+s.

Here it should be mentioned that the rather lowish Hertz measurements are similar to the values of the seven American languages as well as Kwakkel's (2008) findings of Dutch reported on previously in this article. However, the low values might be attributed to the fact that in this case a different microphone was used ${ }^{13}$.

\section{The presence of /s/-fronting}

In some of the cases that were inspected, rather high CoG values for pure /s/ were found. Furthermore, in some cases this is in close association with considerably low CoGs of /s/ when preceded by $/ \mathrm{r} /$, especially when in the same consonant cluster. In the former case a feasible inference could be that the speakers show a tendency towards /s/-fronting of pure $/ \mathrm{s} /$, while at the same time palatalisation of $/ \mathrm{s} /$ in the context of $/ \mathrm{r} /$ is a possibility too. $/ \mathrm{s} /$-fronting has already been observed ${ }^{14}$ independently of the present study. Notably, Bekker (per. comm) argues that it might be indicative of a prestige variant of Afrikaans in this case. On this basis, it makes sense that /s/ is even more markedly fronted in the production of MK (Study 3) in her reading mode in contrast to her spontaneous conversation. In the former context she would have been more self-conscious than otherwise, and perhaps in this respect was making a conscious effort to be posh in her pronunciation, as if doing a public broadcast.

Interestingly, neither palatalisation nor /s/-fronting is present in the speech of the Coloured Afrikaans-speaking persons of Genadendal. /s/-fronting might be in a process of being established in modern Afrikaans, especially in the speech of affluent, youngish, females. This is in a growing degree observable in especially younger, white, female South African English speaking individuals (Bekker 2007).

\section{Conclusion and future work}

This article offered an analysis and description of the CoG of the realisation of /s/ in different contexts in which it followed $/ \mathrm{r}$ /, either in the same syllable (rs\#\#), or in different syllables $(\mathrm{r} \$ \mathrm{~s})$ or across morphemes $(\mathrm{r}+\mathrm{s})$ or words $(\mathrm{r} \# \mathrm{~s})$. The results were taken as an indication of the presence or absence of a process of palatalisation. In some cases, this effect was so obvious that it might be characterised as labialisation. In other instances, only a slight presence of palatalisation was present, most probably not perceivable as such. The most salient of all contexts for possible palatalisation was where /s/ was consistently realised as [J] when occurring tautosyllabically with $/ \mathrm{r} /$ (i.e. in rs\# context). Thus the main hypothesis "The voiceless alveolar fricative /s/, when preceded by /r/, will be pronounced as [ $\left.\int\right]$ in Afrikaans" has been supported.

Different methods of elicitation of speech production were used, ranging from formal (reading of word lists) to informal (spontaneous interview) to a combination of these (reading the transcription of the same spontaneous interview). Across all methods and participatory groups of speakers, /s/ was found in the word-final coda-cluster rs\#\# (e.g. in bars $)$, to be more

\footnotetext{
13 In our experiments we generally compared results obtained using the same microphone, as different microphones may shape the spectrum differently, thereby affecting CoG measurements.

${ }^{14}$ This phenomenon was pointed out by Ian Bekker. We gratefully acknowledge his contribution in this regard.
} 
prominently palatalised than in any other context. This is true for words in the reading lists as well as in both interview types. In most cases, /s/ showed the least palatalisation in multisyllabic words (monomorphemic as well as bimorphemic) than in the other instances.

These abovementioned findings as to the effects of syllable structure on this phenomenon may be considered to be evidence for the existence of word, morpheme and syllable boundaries. Not only does syllable structure play a role in the palatalisation of /s/, vowel quality too, notably the roundedness of vowels adjacent to $r s$ in different contexts, turned out to have a distinct influence on the degree of palatalisation. Surprisingly, in this regard, not only the expected progressive coarticulatory influence was present (more distinctly present in wors, with a rounded vowel, compared to kers, with an unrounded vowel), but to the same degree evidence is found for a regressive pressure towards /s/-palatalisation (thus rounded /y/ in ver-suur causes more palatalisation of /s/ than unrounded /i/ in ver-sier). However, the precise possible interaction between syllable structure and vowel quality in this regard is as yet not quite clear.

The unmistakable prominent presence of this phenomenon in the production of younger speakers, as well as at the same time the seemingly predominant absence thereof in Coloured Afrikaans calls for reflection, and further research. More generally, the occurrence of /s/-palatalisation in Afrikaans calls for an explanation on both phonetic and sociolinguistic grounds.

First of all "normal" palatalisation, in statistical terms all cases of no or small significance (d $=0.0$ up to about $\mathrm{d}=0.2$ ), should most probably be described as cases of normal, low-level phonetic coarticulation. More prominent instances (large differences between pure /s/ and palatalised /s/, viz. [S] $-\mathrm{d}=0.8$ and higher), such as those found in especially younger speakers, beg for an alternative explanation, most probably of the phonological kind. Here three possible explanations are presented for the phenomenon of palatalisation, as well as perhaps /s/-fronting, two of which are phonetic in nature, one of which is phonological. Future follow-up research in both regards is necessary: the use of available modern equipment is planned, notably by using an ultrasound scanner in association with a lip video camera.

From an articulatory perspective, the [r] trill of palatalising speakers is taken to be retroflex in nature, so that coarticulation of $/ \mathrm{s} /$ with such a retroflex [r] could bring about a salient palatalisation of /s/, a palatal position in this case being closer to a retroflex one. Such a possibility necessitates further articulatory study of the production of Afrikaans $/ \mathrm{r} /$, both in isolation and clustered with /s/ in coda position.

A second possible explanation ${ }^{15}$ is perceptual in nature: both older and younger speakers produce a retroflex /r/, which, by means of coarticulation, results in a slightly palatalised realisation of the adjacent $/ \mathrm{s} /$ phoneme. Listeners, on their side, who are confronted with such minor forms of coarticulation then, via a process known as compensation-for-coarticulation, have to perceptually undo such coarticulation. They, therefore, ascribe the palatal characteristics of the realisation of alveolar $/ \mathrm{s} /$ to the adjacent $/ \mathrm{r} /$, and thus identify the fricative as $/ \mathrm{s} /$, not $[\mathrm{S}]$. While this process of compensation is successful in the case of older speakers, this is not the case with the young listeners who, on the contrary, /s/ assume the source of palatalisation not to be $/ \mathrm{r} /$, but in fact to be inherent in /s/ itself. Thus they hear /s/ as [J], and in fact also try to

\footnotetext{
${ }^{15}$ We thank Prof. Andries Coetzee for this particular explanation.
} 
produce the palatal fricative $\left[\int\right]$ in this particular context. Consequently, their realisation of $/ \mathrm{s} /$ is also more palatal than that of the older speakers given that the coarticulatory pressure to palatalise remains in place. In the same vein, the occasional palatal $[S]$ of older speakers can be explained as an attempt by older speakers to imitate the pronunciation of young speakers, which, of course, is not "natural" for them. Further studies based on perception-testing will be essential to confirm or disconfirm this possible explanation.

Finally, our quantification of the degree to which palatalisation of /s/ occurs when preceded by $/ \mathrm{r}$ /, shows the relative contribution of different contexts, one of which shows a high degree of palatalisation in some speakers, namely the word-final context where $r s$ forms a consonant cluster in the syllable coda, denoted as rs\#\#. In this case, the $\mathrm{CoG}$ difference is much larger than the differences associated with measured coarticulation due to vowel influence. One possible reason for this could be that for speakers with an extreme difference (the palatalisers) this is no longer just a matter of coarticulation, but also an act of coda-cluster simplification (McCarthy 2008). Informal observation suggests that the preceding $/ \mathrm{r} /$ might be systematically shortened and that the following /s/ then tends to be more heavily palatalised to compensate for this. In the extreme case words such as /bars/ and /pars/ may be realised as $\left[\mathrm{ba} \int\right]$ and [paf] and still be distinguishable from /bas/ and /pas/. It seems plausible that due to the lack of a $/ \mathrm{J} /$ phoneme in Afrikaans, there is nothing to preclude this and that, in addition, $/ \mathrm{r} /$ is a relatively "unstable" phoneme. It would be interesting to test this hypothesis directly, and future work could start by investigating the duration of $/ \mathrm{r} /$ in this context and a possible relationship between such duration and the degree of palatalisation of the following /s/. If further evidence for coda-cluster simplification is found, this would support distinguishing the causes for the measurements obtained (at least for the "palatalisers") as distinct processes: coarticulation and coda-cluster simplification, with varying degrees of influence on the pronunciation of $/ \mathrm{s} /$ in this context.

\section{References}

Bekker, I. 2007. Fronted /s/ in General White South African English. Language Matters 38(1): 46-74.

Boersma, P. 2001. Praat, a system for doing phonetics by computer. Amsterdam: Glot International.

Boersma, P. and D. Weenink. 2014. Praat: doing phonetics by computer [Computer program]. Version 5.3.84. Available online: http://www.praat.org/ (Accessed 19 Septerber 2015).

Boothroyd, A. and L. Medwetsky. 1992. Spectral distribution of /s/ and the frequency response of hearing aids. Ear and hearing 13(3): 150-157.

Coetzee, A.E. 1981. Fonetiek vir eerstejaars. Pretoria: Academica.

Coetzee, A.W., P.S. Beddor and D.P. Wissing. 2014. Emergent tonogenesis in Afrikaans. The Journal of the Acoustical Society of America 135(4): 2421-2422.

Cohen J. 1988. Statistical power analysis for the behavioural sciences. Hillsdale, NJ: Lawrence Earlbaum Associates. 
Combrink, J.G. and L.G. de Stadler. 1987. Afrikaanse fonologie. Macmillan: South Africa.

Daniloff, R.G., K. Wilcox and M.I. Stephens. 1980. An acoustic-articulatory description of children's defective /s/ productions. Journal of Communication Disorders 13(5): 347-363.

Davel, M. and E. Barnard. 2008. Pronunciation prediction with default and refine. Computer Speech and Language 22(4): 374-393.

Davel, M.H. and F. de Wet. 2010. Verifying pronunciation dictionaries using conflict analysis. In Proceedings of Interspeech. Tokyo, Japan. 2010. pp. 1898-1901.

De Bruto, H.F. and D.P. Wissing. 1972. Aspekte van 'n Afrikaanse TG-fonologie. Johannesburg: McGraw-Hill.

De Villiers, M. and F.A. Ponelis. 1987. Afrikaanse klankleer. Cape Town: Tafelberg

Flipsen, P., L. Shriberg, G. Weismer, H. Karlsson and J. McSweeny. 1999. Acoustic characteristics of /s/ in adolescents. Journal of Speech, Language, and Hearing Research 42(3): 663-677.

Forrest, K., G. Weismer, P. Milenkovic and R.N. Dougall. 1988. Statistical analysis of wordinitial voiceless obstruents: preliminary data. The Journal of the Acoustical Society of America 84(1): 115-123.

Gordon, M., P. Barthmaier and K. Sands. 2002. A cross-linguistic acoustic study of voiceless fricatives. Journal of the International Phonetic Association 32(02): 141-174.

Haley, K.L., E. Seelinger, K.C. Mandulak and D.J. Zajac. 2010. Evaluating the spectral distinction between sibilant fricatives through a speaker-centered approach. Journal of Phonetics 38: 548-554.

Iskarous, K., C.H. Shadle and M.I. Proctor. 2011. Articulatory-acoustic kinematics: The production of American English /s/. The Journal of the Acoustical Society of America 129(2): 944-954.

Jongman, A., R. Wayland and S. Wong. 2000. Acoustic characteristics of English fricatives. The Journal of the Acoustical Society of America 108(3): 1252-1263.

Koenig, L.L., C.H. Shadle, J.L. Preston and C.R. Mooshammer. 2013. Toward improved spectral measures of /s/: Results from adolescents. Journal of Speech, Language, and Hearing Research 56(4): 1175-1189.

Kwakkel, V. 2008. Sibilants in Dutch and English: typologies, learning tasks and language change. Unpublished MA thesis. Universiteit Utrecht. Available online: XX (Accessed XX).

Le Roux, T.H. and R. de V. Pienaar. 1927. Afrikaanse Fonetiek. Cape Town: Juta.

McCarthy, J.J. 2008. The gradual path to cluster simplification. Phonology 25: 271-319. 
McGowan, R.S. and S. Nittrouer. 1988. Differences in fricative production between children and adults: Evidence from an acoustic analysis of $/ \mathrm{J} /$ and $/ \mathrm{s} /$. The Journal of the Acoustical Society of America 83(1): 229-236.

Mielke, J., A. Baker and D. Archangeli. 2010. Variability and homogeneity in American English /r/ allophony and /s/ retraction. Laboratory phonology 10: 699-730.

Munson, B. 2004. Variability in /s/ production in children and adults: Evidence from dynamic measures of spectral mean. Journal of Speech, Language, and Hearing Research 47(1): 58-69.

Perkell, J.S., M.L. Matthies, M. Tiede, H. Lane, M. Zandipour, N. Marrone and F.H. Guenther. 2004. The Distinctness of Speakers' /s/ - / / Contrast is related to their auditory discrimination and use of an articulatory saturation effect. Journal of speech, language, and hearing research, 47(6): 1259-1269.

Shapiro, M. 1995. A case of distant assimilation:/str/ $\rightarrow / \int t r /$. American Speech 70(1): 101-107.

Stevens, K.N. 1998. Acoustic phonetics (Vol. 30). Cambridge, MA; London, England: The MIT Press.

Trafimow, D. 2014. Editorial. Basic and Applied Social Psychology 36(1): 1-2.

Van Niekerk, D.R. and E. Barnard. 2009. Phonetic alignment for speech synthesis in underresourced languages. In Proceedings of Interspeech, Brighton, UK. pp. 880-883.

Whalen, D.H. 1991. Perception of the English /s/ - / / distinction relies on fricative noises and transitions, not on brief spectral slices. The Journal of the Acoustical Society of America 90(4): 1776-1785. 